\title{
Heckman-type selection models to obtain unbiased estimates with missing measures outcome: theoretical considerations and an application to missing birth weight data
}

\author{
Siaka Koné ${ }^{1,2,3^{*}} \mathbb{D}$, Bassirou Bonfoh ${ }^{1,2}$, Daouda Dao ${ }^{1}$, Inza Koné ${ }^{1}$ and Günther Fink ${ }^{2,3}$
}

\begin{abstract}
Background: In low-income settings, key outcomes such as biomarkers or clinical assessments are often missing for a substantial proportion of the study population. The aim of this study was to assess the extent to which Heckman-type selection models can create unbiased estimates in such settings.

Methods: We introduce the basic Heckman model in a first stage, and then use simulation models to compare the performance of the model to alternative approaches used in the literature for missing outcome data, including complete case analysis (CCA), multiple imputations by chained equations (MICE) and pattern imputation with delta adjustment (PIDA). Last, we use a large population-representative data set on antenatal supplementation (AS) and birth outcomes from Côte d'Ivoire to illustrate the empirical relevance of this method.

Results: All models performed well when data were missing at random. When missingness in the outcome data was related to unobserved determinants of the outcome, large and systematic biases were found for CCA and MICE, while Heckman-style selection models yielded unbiased estimates. Using Heckman-type selection models to correct for missingness in our empirical application, we found supplementation effect sizes that were very close to those reported in the most recent systematic review of clinical AS trials.
\end{abstract}

Conclusion: Missingness in health outcome can lead to substantial bias. Heckman-selection models can correct for this selection bias and yield unbiased estimates, even when the proportion of missing data is substantial.

Keywords: Heckman-type selection model, Low birth weight, Antenatal supplementation, Health and demographic surveillance system, Côte d'Ivoire

\section{Background}

A growing literature has highlighted the often substantial differences between evidence based on efficacy trials and empirically observed associations between intervention exposure and health outcomes [1-3]. While this gap may to a certain extent reflect differences in programme implementation and differential adherence to treatment protocols in non-clinical settings, biases in observational studies seem also plausible. A substantial body of

\footnotetext{
* Correspondence: siaka.kone@csrs.ci

${ }^{1}$ Centre Suisse de Recherches Scientifiques en Côte d'Ivoire, 01 BP 1303 Abidjan 01, Côte d'Ivoire

${ }^{2}$ Swiss Tropical and Public Health Institute, Basel CH - 4002, Switzerland Full list of author information is available at the end of the article
}

literature has highlighted the importance of potential confounding variables in observational studies. Slightly less attention has been given to the often substantial degree of missingness in outcome variables [4-6]. Missingness in the outcome variable is of particular importance in the context of clinical data in low-income settings, where accurate measures of clinical outcomes often is only available for a relatively small proportion of the population. Even though missing values can in principle be imputed using multiple imputations [4], this approach can lead to biased estimates if unobservable or unmeasured factors - such as individual health knowledge or attitudes - affect both the outcome of interest and the likelihood of missing data [7].

(c) The Author(s). 2019 Open Access This article is distributed under the terms of the Creative Commons Attribution 4.0 International License (http://creativecommons.org/licenses/by/4.0/), which permits unrestricted use, distribution, and reproduction in any medium, provided you give appropriate credit to the original author(s) and the source, provide a link to the Creative Commons license, and indicate if changes were made. The Creative Commons Public Domain Dedication waiver (http://creativecommons.org/publicdomain/zero/1.0/) applies to the data made available in this article, unless otherwise stated. 
To illustrate the relevance of such non-random missingness in outcome data as well as the possibility to correct for such biases using Heckman-type selection model, we focus on birth weight $(\mathrm{BW})$ as primary outcome variable in this paper. Low birth weight (birth weight $<2500 \mathrm{~g}$ ) affects $15.5 \%$ of children globally [8], and has been identified as one of the primary causes of the continued high burden of under-5 mortality in low-and middle-income countries [9]. In low income settings, birth weight is only available for women who deliver at a health centres with functioning measurement equipment as well as staff willing and able to record infant weight after birth. Given that institutional deliveries remain scarce in many settings [10], reliable data can often only be attained for a limited proportion of women. Missing outcome data will not cause systematic bias if data are missing at random (MAR). In practice, the MAR assumption will, however, not hold if unobservable traits such as preventive efforts or health knowledge predict both the likelihood to deliver at a facility (the likelihood of having birth weight data available) and the actual health outcome of interest.

The selection model introduced by Heckman [7] provides a potentially useful tool in this situation, since it allows to both test and correct for potential biases created by nonrandom missingness in outcome measures. To illustrate this, we first use Monte-Carlo simulations to assess the relative ability of different models to detect true causal effects. The specific causal effect we investigate is the effect of antenatal supplementation on birth weight. Iron and folic acid supplementation (IFAS) is widely recognized as one of the most effective interventions to address low birth weight (LBW). A meta-analysis of 11 trials revealed a reduction of the risk of LBW by $20 \%$ associated with iron supplementation or when iron supplementation was combined with folic acid (relative risk [RR] 0.80, 95\% CI 0.71-0.90) [11]. The same patterns have generally not been found in observational studies [12-14]. We first assess the extent to which Heckman selection models, namely complete case analysis (CCA), multiple imputations by chained equations (MICE) and pattern imputation with delta adjustment (PIDA), can recover the true causal impact of interest in simulated data in a first step. In a second step, we illustrate these differences using population-representative data on antenatal supplementation (AS) and birth weight from the health and demographic surveillance site (HDSS) in Taabo, Côte d'Ivoire.

\section{Methods}

\section{Objective and modelling background}

The main objective of this paper is to compare Heckman-type selection models to alternative approaches used to deal with missing outcome data in the literature. The Heckman model includes two separate equations - one focusing on selection into the sample (outcome being observed - the sample selection equation), and the main equation linking the covariates of interest to the outcome.

The two Heckman equations for two latent responses $y_{i}^{*}$ (the outcome) and $s_{i}^{*}$ (the selection propensity variable) can be stated as follows [15]:

$$
\begin{aligned}
& y_{i}^{*}=x_{i}^{\prime} \beta+\mu_{i} \\
& s_{i}^{*}=z_{i}^{\prime} \gamma+v_{i}
\end{aligned}
$$

Where $y_{i}^{*}$ and $s_{i}^{*}$ are unobserved latent continuous variables, $x_{i}^{\prime}$ and $z_{i}^{\prime}$ are vectors of predictor variables. In general, $x$ is assumed to be a subset of $z$, which means that all factors predicting the main outcome of interest $(y)$ also predict selection $s . \mu$ and $v$ are normally distributed error term, and $\beta$ is the primary parameter vector of interest. Outcome variables are observed if the latent selection propensity exceeds zero, i.e.:

$$
s_{i}=\left(\begin{array}{ccc}
1 & \text { if } & s_{i}^{*}>0 \\
0 & \text { if } & s_{i}^{*} \leq 0
\end{array}\right)
$$

The main idea of the Heckman model is that it seems theoretically rather likely that unobservable or unmeasured factors may affect both the outcome $y$ and the probability of selection $s$; these unmeasured factors would be contained in the residuals of both equation (1) and equation (2). Given selection into the main sample, the expected value of the outcome in the main equation is given by:

$$
E(y \mid z, v)=x \beta+E(\mu \mid v)
$$

Given that the covariates $x$ and $v$ jointly determine selection into the sample, $\operatorname{cov}(x, v \mid s=1)$ is non-zero in general, so that beta estimates will be both biased and inconsistent if $\mu$ and $v$ are correlated. This correlation is straightforward to estimate empirically by fitting independent models for $y$ and $s$, and computing the covariance between the two residual terms. Heckman shows that this bias can be corrected by computing the expected value of $v$ conditional on $z$ and being in the sample, and by including this term in the main empirical model. Consistent estimators can be obtained by maximum likelihood jointly estimating the first stage with a probit model as well as the main equation of interest including the expected value of the selection equation residuals [15].

\section{Study variables}

The main outcome variables used were continuous birth weight (BW) as well as binary indicator for LBW (weight $<2500 \mathrm{~g})$.

Additional variables used for the analysis of our demographic surveillance data are socioeconomic 
status and distance to facility. Socioeconomic status was determined using a household-based asset approach and principal component analysis (PCA) to divide households into wealth quintile (poorest, poor, medium, rich and richest) [16]. Using household and health centres geographical coordinates, we estimated the distance from mother's place of residence to the nearest health facility by means of the Statageodist package [17].

\section{Simulations and statistical analysis}

Our empirical analysis is divided into two parts. In the first part, we use Monte-Carlo simulations to illustrate the empirical performance of CCA, MICE, PIDA and Heckman with missing outcome data. Based on the empirical data used in the second part of the analysis, we assume a sample size of 10,000 births, and normally distributed birth weight with mean $3000 \mathrm{~g}$, and standard deviation of $500 \mathrm{~g}$. Based on the most recent systematic review, we assume that supplementation linearly increases birth weight by $50 \mathrm{~g}$. We first assume that $40 \%$ of the outcome data are missing at random, and plot the estimated coefficients on supplementation based on 1000 randomly created data sets. In a second step, we assume that missing outcome data is a function of unobserved health knowledge, and that unobserved health knowledge is also predictive of birth weight. For the data generating process, we assume that health knowledge follows a standard normal distribution, and that each standard deviation (SD) increase in health knowledge increases birth weight by $100 \mathrm{~g}$. We also assume the probability of delivering increases with the unobserved health knowledge variable, and decreases with household distance from the facility. We then test the various modelling approaches under this "endogenous selection" (as Heckman refers to it) scenario.

To illustrate the empirical relevance of this approach, we use a large population-representative data set on antenatal iron and folic acid supplementation (IFAS) and birth outcomes from the Taabo HDSS in Côte d'Ivoire. We first use the Heckman model to directly test for endogenous sample selection, and then compare Heckman-corrected estimates to complete case analysis. In a second step, we also explore MICE and PIDA model to compare the relative performance of these tools in the setting studied. MICE was done with a number of 150 imputations using Stata multiple imputations (mi) package [18]. For the multiple imputations, we created a prediction model for BW with missing values from all other variables. All variables included in Appendix Table 4 were included in the imputation models.

All statistical analyses were performed in Stata version 12.0 (StataCorp; College Station, TX, USA).

\section{Study area}

The empirical data used in this study were collected through the Taabo HDSS $[19,20]$. The Taabo HDSS is located in the Agnéby-Tiassa region in south-central Côte d'Ivoire. It covers a surface area of approximately $980 \mathrm{~km}^{2}$ located between latitude $6^{\circ} 0^{\prime}$ and $6^{\circ} 20^{\prime} \mathrm{N}$ and between longitude $4^{\circ} 55^{\prime}$ and $5^{\circ} 15^{\prime} \mathrm{W}$.

The area is predominantly rural, with 13 main villages and more than 100 small hamlets. Within the study zone there are 11 health facilities, including seven health centres and four dispensaries in the rural area, and a 12-bed hospital located in Taabo-Cité considered as semi-urban (Fig. 1).

\section{Data collection}

All women of reproductive age (15-49 years) from the Taabo HDSS whose pregnancy started and ended between January 1, 2012 and December 31, 2017 were included. Each household of the Taabo HDSS was visited at least three times a year during this period for detailed surveillance of vital events (i.e. birth, death, in-migration, out-migration and pregnancy). During each surveillance round, new pregnancies were systematically listed and followed-up longitudinally. When a pregnancy was completed (independent of the outcome), a standardized questionnaire on pregnancy-related morbidity was administered by field-enumerators through a personal interview with mothers [21]. This questionnaire included information on pregnancy outcome and morbidity, iron and folic acid supplementation (IFAS), birth weight, place of delivery, and birth assistance. All data were double-entered, cross-checked, and managed using a household registration system implemented in Windev version 12.0 (PC Soft, Montpellier, France) [22].

\section{Simulation results}

Figure 2 summarizes the main results from the MonteCarlo simulations. One thousand random data sets with 10, 000 observations in each random draw were created and analyzed. Without missingness, estimated ordinary least squares (OLS) coefficients were normally distributed around the true causal effect of 50 as expected (Fig. 2, panel 1). With $40 \%$ missing at random (Fig. 2, panel 2), OLS is still unbiased with slightly decreased efficiency. In panels $3-5$, we present results under the assumption that missingness is correlated with an unobserved determinant of birth weight. As seen in panel 3, OLS estimates are severely biased towards zero in this scenario. MICE (panel 4) changes these results only marginally. As shown in panel 5 , the Heckman model is able to remove this bias completely and recovers unbiased estimates, even though the variation 


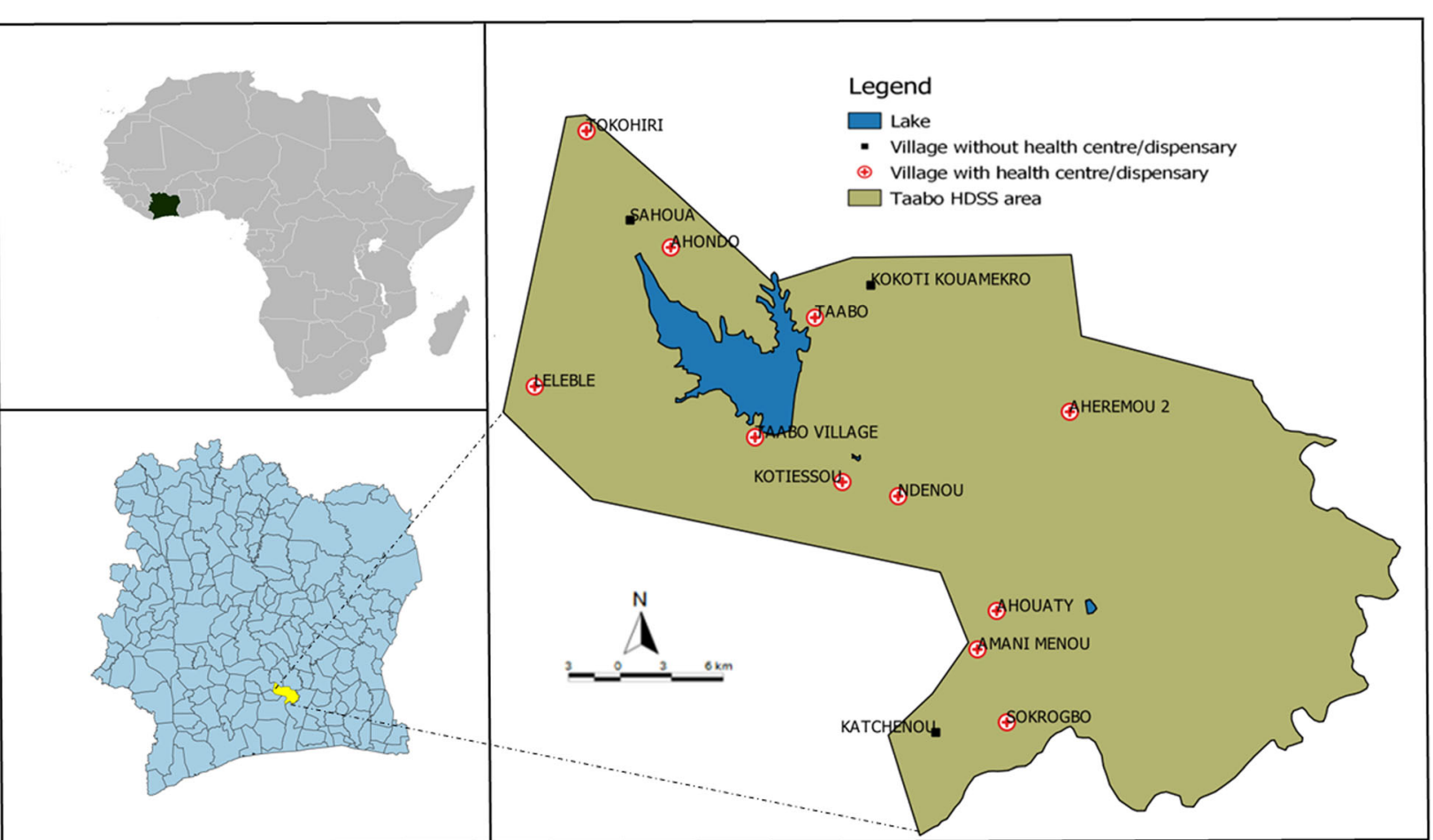

Fig. 1 Map of the Taabo health and demographic surveillance system (HDSS) in south-central Côte d'Ivoire

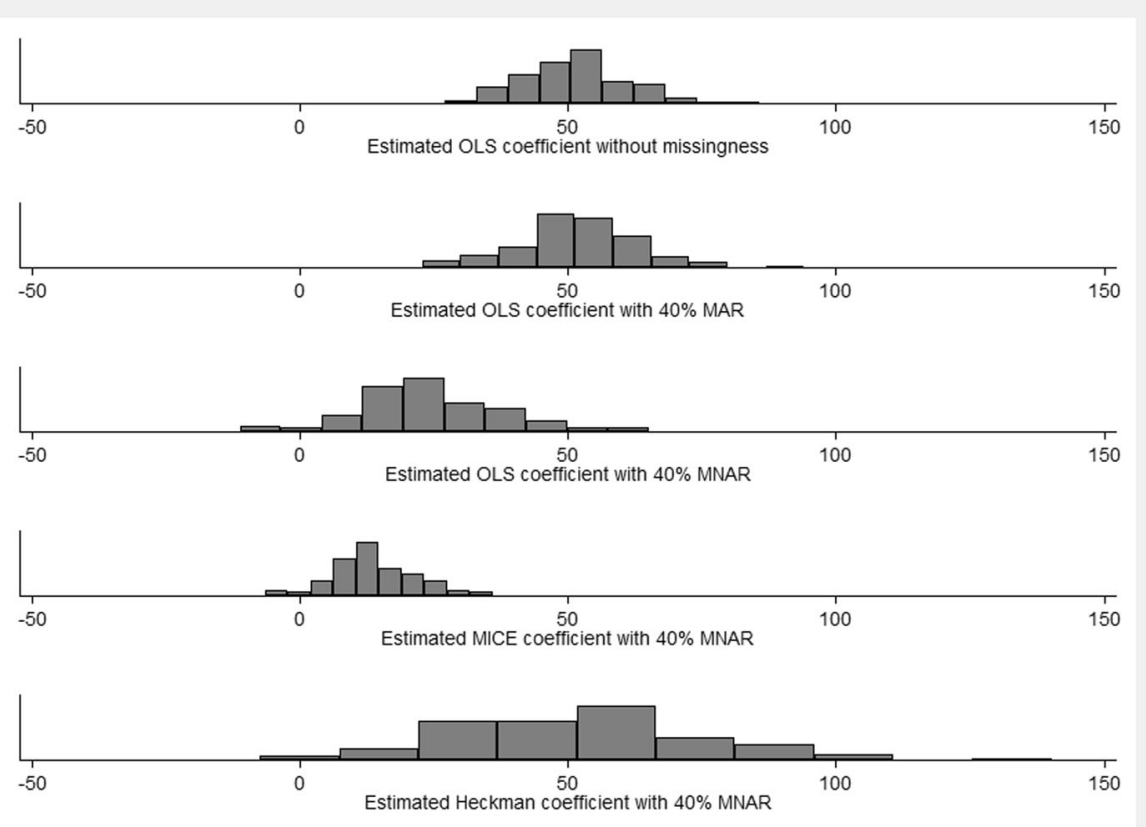

Fig. 2 Monte Carlo Simulation Results. Shows empirical distribution of estimates in Monte Carlo Simulation and are based on 1000 random data draws. OLS: ordinary least squares. MAR: missing at random. MNAR: missing not at random. MICE: Multiple imputations by chained equation 


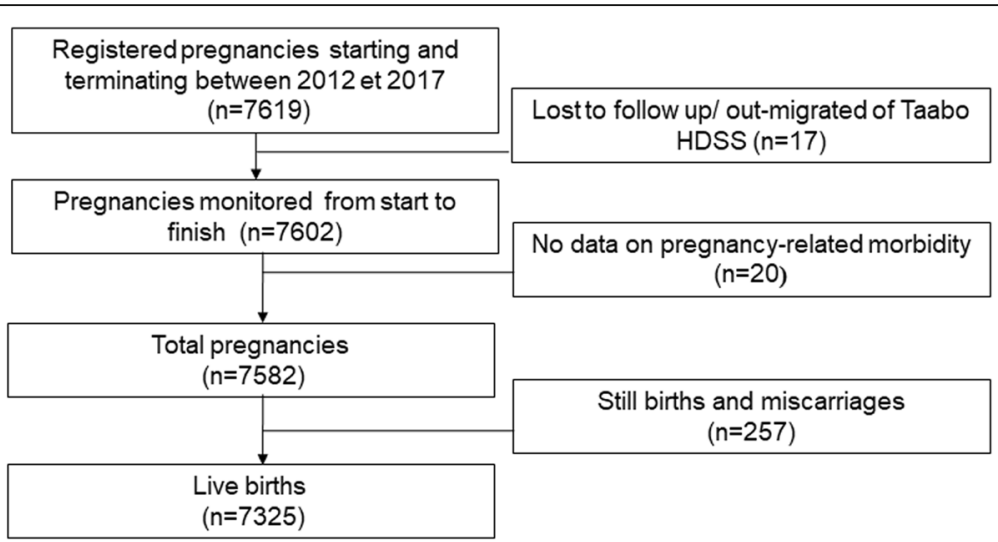

Fig. 3 Structure of pregnancies monitoring in the Taabo health and demographic surveillance system in south-central Côte d'Ivoire (2012-2017)

Table 1 Associations between IFAS and birth weight

\begin{tabular}{|c|c|c|c|c|c|c|c|c|}
\hline \multicolumn{5}{|c|}{ Linear regression } & \multicolumn{4}{|c|}{ Heckman Model } \\
\hline \multirow[t]{2}{*}{ Variable } & \multicolumn{2}{|c|}{ Unadjusted coeff } & \multicolumn{2}{|c|}{ Adjusted coeff } & \multicolumn{2}{|c|}{ Unadjusted coeff } & \multicolumn{2}{|c|}{ Adjusted coeff } \\
\hline & Coeff & $95 \% \mathrm{Cl}$ & Coeff & $95 \% \mathrm{Cl}$ & Coeff & $95 \% \mathrm{Cl}$ & $\overline{\text { Coeff }}$ & $95 \% \mathrm{Cl}$ \\
\hline \multicolumn{9}{|l|}{ IFAS: $\mathrm{No}^{(+)}$} \\
\hline Yes & $27.08^{*}$ & $-3.49 ; 57.66$ & 22.48 & $-13.73 ; 58.69$ & $38.82^{* *}$ & $6.66 ; 70.97$ & $53.19^{* * *}$ & $12.76 ; 93.63$ \\
\hline \multicolumn{9}{|c|}{ Educational attainment: No schooling ${ }^{(+)}$} \\
\hline \multicolumn{3}{|l|}{ Primary } & 19.87 & $-13.53 ; 53.28$ & & & 19.18 & $-14.16 ; 52.53$ \\
\hline \multicolumn{3}{|l|}{ Coranic } & 35.95 & $-26.13 ; 98.02$ & & & 34.48 & $-27.51 ; 96.47$ \\
\hline \multicolumn{3}{|c|}{ Secondary or higher } & $49.39^{* *}$ & $1.52 ; 97.27$ & & & $45.12^{*}$ & $-2.75 ; 92.99$ \\
\hline \multicolumn{9}{|c|}{ Maternal age (years): $20-34^{(+)}$} \\
\hline \multicolumn{3}{|l|}{$15-19$} & $-209.60^{* * *}$ & $-252.60 ;-166.60$ & & & $-209.84^{* * *}$ & $-252.73 ;-166.95$ \\
\hline \multicolumn{3}{|l|}{$35-49$} & 6.97 & $-37.70 ; 51.63$ & & & 2.54 & $-42.12 ; 47.21$ \\
\hline \multicolumn{9}{|c|}{ Socioeconomic status: Most poor ${ }^{(+)}$} \\
\hline \multicolumn{3}{|l|}{ Poor } & 33.76 & $-16.13 ; 83.64$ & & & 30.70 & $-19.09 ; 80.50$ \\
\hline \multicolumn{3}{|l|}{ Middle } & 25.64 & $-24.09 ; 75.37$ & & & 18.98 & $-30.80 ; 68.75$ \\
\hline \multicolumn{3}{|l|}{ Rich } & -0.10 & $-49.72 ; 49.52$ & & & -8.85 & $-58.63 ; 40.93$ \\
\hline \multicolumn{3}{|c|}{ Most rich } & $53.73^{*}$ & $-3.79 ; 111.30$ & & & 44.70 & $-12.96 ; 102.37$ \\
\hline \multicolumn{9}{|c|}{ Child sex: Male ${ }^{(+)}$} \\
\hline \multicolumn{3}{|l|}{ Female } & $-124.70^{* * *}$ & $-153.20 ;-96.19$ & & & $-123.36^{* * *}$ & $-151.74 ;-94.98$ \\
\hline \multicolumn{9}{|c|}{ Previous births: 0 child ${ }^{(+)}$} \\
\hline \multicolumn{3}{|l|}{$1-4$} & 54.38 & $-18.11 ; 126.90$ & & & 54.50 & $-17.87 ; 126.87$ \\
\hline \multicolumn{3}{|c|}{$\geq 5$} & $181.50^{* * *}$ & $98.92 ; 264.10$ & & & $184.51^{* * *}$ & $102.08 ; 266.94$ \\
\hline \multicolumn{9}{|c|}{ Twin births: $\mathrm{No}^{(+)}$} \\
\hline \multicolumn{3}{|l|}{ Yes } & $-640.40^{* * *}$ & $-701.60 ;-579.30$ & & & $-644.78^{* * *}$ & $-705.91 ;-583.65$ \\
\hline Constant & $2959^{* * *}$ & 2937; 2980 & $2953^{* * *}$ & $2855 ; 3051$ & $2972.88^{* * *}$ & $2948.28 ; 2997.48$ & $3143.06^{* * *}$ & $3026.61 ; 3259.52$ \\
\hline R-squared & 0.001 & & 0.143 & & & & & \\
\hline lambda & & & & & $-47.75^{* *}$ & $-88.24 ;-7.25$ & $-79.24^{* * *}$ & $-126.05 ;-32.42$ \\
\hline observations & 4510 & & 4510 & & 7325 & & 7325 & \\
\hline
\end{tabular}

*** $p<0.01 .{ }^{* *} p<0.05 .^{*} p<0.1 i^{(+)}$Reference category; Adjusted model controls village fixed effects; $C$ Confidence interval 
observed across estimates is substantially larger than the variation observed in OLS models.

\section{Empirical application: antenatal supplementation and birth weight in the Taabo HDSS}

Description of study population

Between 2012 and 2017, a total of 7619 pregnancies were reported and 7602 pregnancies were followed up after delivery (Fig. 3). Seventeen pregnancies were lost to follow-up due to out-migration of the women. Twenty records were dropped due to missing information on pregnancy-related morbidity. Overall 7542 monitored pregnancies had complete data records, and hence, were considered as final study sample. Within these fully monitored pregnancies, 7325 resulted in live births, 185 were still births, and 73 were miscarriages. Birth weight was observed for 4510 births, and unobserved for 2815 births.

Appendix Table 4 shows characteristics of women in the sample overall as well as for women who benefitted from IFAS. Over half of the women in the study had no educational attainment $(54.9 \%)$ and could not write and read (73.6\%). IFAS was received by 3260 (44.5\%) of pregnant women.

\section{Associations between IFAS, LBW and birth weight}

Table 1 shows the main estimation results for continuous birth weight. In fully adjusted OLS models, IFAS was associated with a non-significant $22.5 \mathrm{~g}$ increase (95\% confidence interval $(95 \% \mathrm{CI})=-13.7,58.7 ; p$ value $=0.224$ ) in BW using OLS. In the Heckman model, the estimated increase in weight was $53.2 \mathrm{~g}$ (95\% CI: 12.7, 93.6; $p$-value =0.010). Appendix Table 5 and Appendix Table 6 compare the predicted effects of IFAS on LBW, as well as the estimated association between LBW and the other variables, from alternative multilevel logistic, MICE and Heckman probit models, respectively. In the complete cases logistic model with controls for village of residence, IFAS was not associated with higher odds of having a LBW ( $p$-value $=$ 0.626). Using Heckman's model to correct for endogenous selection IFAS was associated with a 10.4 percentage point reduction in the probability of LBW (95\% CI: $0.169 ;-0.039 ; p$-value $=0.002$ ).

In both the binary dependent variable model (Appendix Table 4) and the continuous variable model (Table 1), the null hypothesis of independent residuals $(\operatorname{cov}(\mathrm{u}, \mathrm{v})=0)$ was rejected with $p$-value $<$ 0.01 .

Estimated selection probabilities: birth weight availability Table 2 shows the results from the selection equation. As expected, data availability was strongly correlated
Table 2 Estimated selection probabilities from probit models

\begin{tabular}{|c|c|c|c|c|}
\hline \multicolumn{5}{|l|}{ Probit models } \\
\hline \multirow[t]{2}{*}{ Variable } & \multicolumn{2}{|c|}{ Unadjusted coeff } & \multicolumn{2}{|c|}{ Adjusted coeff } \\
\hline & $\mathrm{dy} / \mathrm{dx}$ & $95 \% \mathrm{Cl}$ & $d y / d x$ & $95 \% \mathrm{Cl}$ \\
\hline \multicolumn{5}{|l|}{ IFAS: $\mathrm{No}^{(+)}$} \\
\hline Yes & $0.171^{* * *}$ & $0.150 ; 0.192$ & $0.243^{* * *}$ & $0.221 ; 0.265$ \\
\hline \multicolumn{5}{|l|}{ Distance } \\
\hline Distance & $-0.024^{* * *}$ & $-0.027 ;-0.021$ & -0.000 & $-0.006 ; 0.005$ \\
\hline \multicolumn{5}{|c|}{ Educational attainment: No schooling ${ }^{(+)}$} \\
\hline \multicolumn{3}{|l|}{ Primary } & $0.025^{* *}$ & $0.002 ; 0.048$ \\
\hline \multicolumn{3}{|l|}{ Coranic } & 0.014 & $-0.033 ; 0.062$ \\
\hline \multicolumn{3}{|c|}{ Secondary or higher } & $0.080^{* * *}$ & $0.044 ; 0.117$ \\
\hline \multicolumn{5}{|c|}{ Marital status: Unmarried ${ }^{(+)}$} \\
\hline \multicolumn{3}{|c|}{ Common-law union } & -0.019 & $-0.057 ; 0.019$ \\
\hline \multicolumn{3}{|l|}{ Married } & $0.064^{* * *}$ & $0.024 ; 0.103$ \\
\hline \multicolumn{3}{|c|}{ Divorced/widowed } & 0.055 & $-0.061 ; 0.170$ \\
\hline \multicolumn{5}{|c|}{ Maternal age (years): 20-34 } \\
\hline \multicolumn{3}{|l|}{$15-19$} & 0.016 & $-0.014 ; 0.047$ \\
\hline \multicolumn{3}{|l|}{$35-49$} & $0.051^{* * *}$ & $0.021 ; 0.081$ \\
\hline \multicolumn{5}{|c|}{ Socioeconomic status: Most poor ${ }^{(+)}$} \\
\hline \multicolumn{3}{|l|}{ Poor } & 0.018 & $-0.013 ; 0.048$ \\
\hline \multicolumn{3}{|l|}{ Middle } & $0.097^{* * *}$ & $0.065 ; 0.129$ \\
\hline \multicolumn{3}{|l|}{ Rich } & $0.100^{* * *}$ & $0.068 ; 0.131$ \\
\hline \multicolumn{3}{|l|}{ Most rich } & $0.105^{* * *}$ & $0.066 ; 0.145$ \\
\hline \multicolumn{5}{|l|}{ Anaemia: $\mathrm{No}^{(+)}$} \\
\hline \multicolumn{3}{|l|}{ Yes } & $0.050^{* * *}$ & $0.021 ; 0.079$ \\
\hline \multicolumn{5}{|c|}{ Lack of appetite: $\mathrm{No}^{(+)}$} \\
\hline \multicolumn{3}{|l|}{ Yes } & $0.039^{* * *}$ & $0.014 ; 0.064$ \\
\hline \multicolumn{5}{|c|}{ Previous births: 0 child $^{(+)}$} \\
\hline \multicolumn{3}{|l|}{$1-4$} & -0.029 & $-0.086 ; 0.028$ \\
\hline \multicolumn{3}{|l|}{$\geq 5$} & $-0.092^{* * *}$ & $-0.154 ;-0.029$ \\
\hline \multicolumn{5}{|c|}{ Twin births: $\mathrm{No}^{(+)}$} \\
\hline Yes & & & $0.092^{* * *}$ & $0.043 ; 0.140$ \\
\hline observations & 7325 & & 7325 & \\
\hline
\end{tabular}

${ }^{* * *} p<0.01 .{ }^{* *} p<0.05 .^{*} p<0.1 i^{(+)}$Reference category; $\mathrm{dy} / \mathrm{dx}=$ Marginal effect is a change in the probability that $Y=1$ with a specific change in $X$. Adjusted model controls village fixed effects; $\mathrm{Cl}$ Confidence interval

with socioeconomic variables as well as supplementation. Compared to women without schooling, women with secondary or higher education had an 8.0 percentage points (95\% CI: $0.044,0.117 ; p$-value $<0.00)$ higher propensity to have data available. Similarly, compared to the poorest households, women from the top two wealth quintiles of households had 10.0 (95\% CI: 0.068, 0.131; $p$ value $=0.00)$ and 10.5 percentage points $(95 \% \mathrm{CI}$ : 0.066 , $0.145 ; p$-value $<0.00$ ) higher probability of having data available. IFAS increased the probability by 24.3 percentage points (95\% CI: $0.221,0.265$; $p$-value $<0.00$ ). 
Table 3 Models imputing outcome variables

\begin{tabular}{|c|c|c|c|c|c|}
\hline \multirow{3}{*}{$\begin{array}{l}\text { Outcome variable } \\
\text { Variable }\end{array}$} & \multicolumn{5}{|l|}{ Birth weight in grams } \\
\hline & \multicolumn{2}{|l|}{ Imputation } & \multicolumn{3}{|l|}{ PIDA } \\
\hline & Mean imputation & MICE & $\begin{array}{l}\text { Group Mean } \\
\text { replacement }^{\mathrm{a}}\end{array}$ & $-0.5 \mathrm{SD}^{\mathrm{b}}$ & $+0.5 \mathrm{SD}^{c}$ \\
\hline \multicolumn{6}{|l|}{ IFAS: No } \\
\hline Yes & $7.02(-13.97 ; 28.01)$ & $22.38(-13.49 ; 58.26)$ & $18.71^{*}(-2.27 ; 39.69)$ & $\begin{array}{l}-51.78^{* * *}(-73.76 ;- \\
29.80)\end{array}$ & $76.78^{* * *}(54.99 ; 98.57)$ \\
\hline \multicolumn{6}{|c|}{ Educational attainment: No schooling ${ }^{(+)}$} \\
\hline Primary & $10.96(-9.75 ; 31.66)$ & $20.03(-12.71 ; 52.77)$ & $10.98(-9.72 ; 31.68)$ & $13.73(-7.96 ; 35.41)$ & $7.98(-13.52 ; 29.48)$ \\
\hline Coranic & $22.96(-19.61 ; 65.52)$ & $36.12(-26.93 ; 99.17)$ & $23.34(-19.22 ; 65.89)$ & $36.71(-7.87 ; 81.29)$ & $8.31(-35.88 ; 52.51)$ \\
\hline $\begin{array}{l}\text { Secondary or } \\
\text { higher }\end{array}$ & $32.13^{*}(-0.03 ; 64.30)$ & $49.47^{* *}(0.90 ; 98.03)$ & $32.09 *(-0.06 ; 64.25)$ & $45.41^{* * *}(11.72 ; 79.09)$ & $17.79(-15.61 ; 51.18)$ \\
\hline \multicolumn{6}{|c|}{ Maternal age (years): $20-34^{(+)}$} \\
\hline $15-19$ & $\begin{array}{l}-133.30^{* * *}(-160.60 ;- \\
106.00)\end{array}$ & $\begin{array}{l}-209.30^{* * *}(-253.10 ;- \\
165.50)\end{array}$ & $\begin{array}{l}-133.92^{* * *}(-161.23 ;- \\
106.61)\end{array}$ & $\begin{array}{l}-131.68^{* * *}(-160.29 \\
-103.07)\end{array}$ & $\begin{array}{l}-135.34^{* * *}(-163.71 ;- \\
106.98)\end{array}$ \\
\hline $35-49$ & $9.22(-19.01 ; 37.44)$ & $6.91(-36.48 ; 50.30)$ & $9.46(-18.76 ;-37.67)$ & $24.99 *(-4.57 ; 54.54)$ & $-7.68(-36.98 ; 21.62)$ \\
\hline \multicolumn{6}{|c|}{ Socioeconomic status: Most poor ${ }^{(+)}$} \\
\hline Poor & $14.68(-14.16 ; 43.52)$ & $32.48(-18.42 ; 83.39)$ & $14.43(-14.40 ; 43.27)$ & $21.87(-8.33 ; 52.07)$ & $6.79(-23.16 ; 36.74)$ \\
\hline Middle & $13.04(-17.00 ; 43.08)$ & $25.15(-24.63 ; 74.93)$ & $12.77(-17.26 ; 42.79)$ & $42.02^{* * *}(10.57 ; 73.48)$ & $-18.40(-49.58 ; 12.79)$ \\
\hline Rich & $-1.75(-31.22 ; 27.71)$ & $-0.52(-53.46 ; 52.41)$ & $-1.93(-31.39 ; 27.52)$ & $27.05^{*}(-3.81 ; 57.91)$ & $-32.94^{* *}(-63.54 ;-2.35)$ \\
\hline Most rich & $35.31^{*}(-0.68 ; 71.30)$ & $53.72^{*}(-4.44 ; 111.90)$ & $35.06^{*}(-0.92 ; 71.03)$ & $66.49^{* * *}(28.80 ; 104.18)$ & $1.52(-35.84 ; 38.89)$ \\
\hline \multicolumn{6}{|l|}{ Child sex: Male ${ }^{(+)}$} \\
\hline Female & $\begin{array}{l}-80.03^{* * *}(-97.96 ;- \\
62.09)\end{array}$ & $\begin{array}{l}-125.20^{* * *}(-153.80 ;- \\
96.59)\end{array}$ & $\begin{array}{l}-80.17^{* * *}(-98.10 ;- \\
62.24)\end{array}$ & $\begin{array}{l}-80.28^{* * *}(-99.06 ;- \\
61.50)\end{array}$ & $\begin{array}{l}-79.83^{* * *}(-98.45 ;- \\
61.21)\end{array}$ \\
\hline \multicolumn{6}{|c|}{ Previous births: 0 child ${ }^{(+)}$} \\
\hline $1-4$ & $44.13^{*}(-2.89 ; 91.15)$ & $57.12(-17.29 ; 131.50)$ & $44.35^{*}(-2.65 ;-91.35)$ & $40.49(-8.75 ; 89.73)$ & $48.18^{*}(-0.64 ; 96.10)$ \\
\hline$\geq 5$ & $112.30^{* * *}(59.65 ; 164.90)$ & $\begin{array}{l}186.30^{* * *}(100.60 ;- \\
272.00)\end{array}$ & $112.38^{* * *}(59.77 ; 165.00)$ & $94.30^{* * *}(39.17 ; 149.43)$ & $131.75^{* * *}(77.10 ; 186.40)$ \\
\hline \multicolumn{6}{|l|}{ Twin births: $\mathrm{No}^{(+)}$} \\
\hline Yes & $\begin{array}{l}-476.80^{* * *}(-518.80 ;- \\
434.80)\end{array}$ & $\begin{array}{l}-642.10^{* * *}(-702.90 ;- \\
581.40)\end{array}$ & $\begin{array}{l}-476.64^{* * *}(-518.62 ;- \\
434.66)\end{array}$ & $\begin{array}{l}-452.14^{* * *}(39.18 \\
149.42)\end{array}$ & $\begin{array}{l}-503.37^{* * *}(-546.98 ;- \\
459.78)\end{array}$ \\
\hline observations & 7325 & 7325 & 7325 & 7325 & 7325 \\
\hline
\end{tabular}

MICE Multiple imputations by chained equation. MICE was done with 150 imputations using Stata mi estimate package PIDA Pattern imputation with delta adjustment

${ }^{a}$ Missing values were replaced with mean of group (mean of observed birth weight for treated, and mean of observed birth weight for non-treated for control)

${ }^{b}$ Missing values were replaced with a birth weight half a standard deviation lower than the observed mean.

${ }^{c}$ Missing values were replaced with a birth weight half a standard deviation above the observed mean.

${ }_{* * *} p<0.01$. ${ }^{* *} p<0.05 .^{*} p<0.1 i^{(+)}$Reference category; Adjusted model controls village fixed effects; Cl: confidence interval

\section{IFAS effect on BW using alternative methods}

Table 3 shows results of mean imputation, MICE and three potential PIDA scenarios. Using mean imputation and MICE, a non-significant association was found between BW and IFAS. While the estimates from the MICE model were almost identical to those found in the CCA (Table 1), mean imputation lowered the estimated association to a non-significant 7.02 g (95\% CI: - 13.97; 28.01). The right hand side of Table 3 shows the PIDA results, and strongly highlights the sensitivity of the empirical model to the assumed patterns in the missing data. In PIDA scenario
1 (where missing BW data were replaced with group means) and scenario 3 (when missing BW data were replaced with BW half a SD above the mean) IFAS was associated with significant $18.7 \mathrm{~g}$ (95\% CI: -2.27 , 39.69) and $76.8 \mathrm{~g}$ (95\% CI: 54.10, 98.57) increase in BW. When missing values were replaced with values half a standard deviation below the mean (scenario 2), IFAS was associated with a $51.8 \mathrm{~g}(95 \% \mathrm{CI}$ : 73.76 ; - 29.80) decrease in BW.

Figure 4 summarizes the estimated coefficients of all models considered and shows them relative to the latest systematic review. 


\section{Effect of IFAS on birth weight}

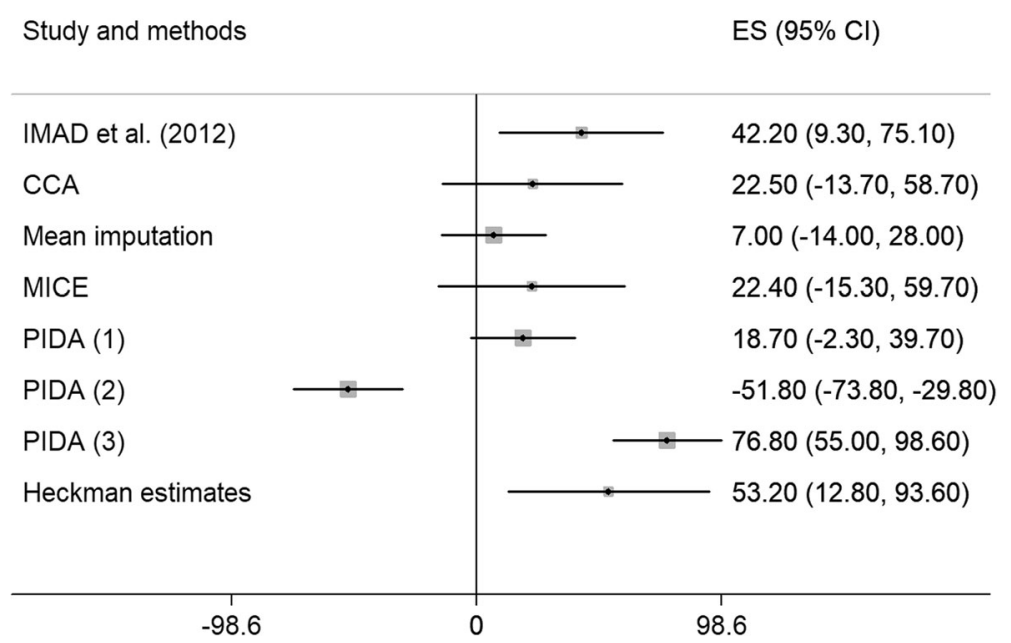

Fig. 4 Comparison of IFAS effect on BW using alternative methods. Compares IFAS effect estimates from the systematic review in Imad et al. to estimates obtained in the HDSS data using the following missing data approaches: complete case analysis, mean imputation, multiple imputations by chained equations (MICE), and three alternativepattern imputation with delta adjustment ( PIDA) as well as Heckman estimates. For PIDA (1), missing BW data were replaced with group means. For PIDA (2) missing BW data were replaced with BW half a standard deviation below the mean. For PIDA (3), missing BW data were replaced with BWt half a standard deviation above the mean. Effect sizes (ES) represent grams, with $95 \%$ confidence intervals in parentheses

\section{Discussion}

In this study, we have shown that Heckman-type selection models can be used to assess and correct potential nonrandom missingness of outcome data in the context of $\mathrm{BW}$ and micronutrient supplementation in low-income setting. Using simulated data, we show that bias will always emerge in standard empirical models if unobserved determinants of the outcome also predict the availability of outcome measures. Using recent data from a HDSS in Côte d'Ivoire, we then show that missingness in BW does indeed seem to correlate with unobserved maternal traits that jointly predict availability and health outcomes. This correlation between unobserved selection determinants and health outcomes leads to substantial biases in traditional regression models that cannot be removed by alternative imputation models, but generally appears to be well accounted for in Heckman models.

In terms of alternative approaches, we also show that PIDA can in principle recover unbiased estimates. The main challenge with this approach is that identifying the most realistic scenario is not obvious. Given that the range of potential assumptions is rather large, PIDA methods seem most useful for illustrating the sensitivity of regression results with respect to missing data assumptions. The study presented here has several limitations. First, given the observational nature of the data, we do not know the true causal effect of IFAS in our empirical application; while we can use the latest systematic review on this intervention as reference benchmark; this benchmark does not need to necessarily hold in our setting so that we cannot directly assert the unbiasedness of the Heckman estimation. Our simulation model also assumed normal residuals, which may not always be the case. Several recent papers suggest that nonnormal residual distributions can relatively easily be incorporated in this model [23, 24]. Second, it is also important to highlight that the rate of missing BW data is rather high in our study setting, so that the differences we found across models would likely be smaller in settings with better data coverage. From a health perspective, the data used in the last part of the study is relatively coarse and did not allow to separate the effects of iron and folic acid supplementation. Similarly, we were also not able to test for frequency of dosage effects of these supplements, which have been shown to be important in previous studies $[25,26]$.

\section{Conclusion}

The results presented in this study suggest that missing outcome data can lead to substantial biases in observational studies assessing the cross-sectional associations between programme coverage and health outcomes. Heckman selection models appear to be well suited to address this potential bias and should be more widely used to address nonrandom missingness in outcome data.

\section{Abbreviations}

AS: Antenatal supplementation; BW: Birth weight; CCA: Complete case analysis; Cl: Confidence interval; CSRS: Centre Suisse de Recherches Scientifiques en Côte d'Ivoire; FAIRMED: Santé pour les plus démunis; HDSS: Health and demographic surveillance system; IFAS: Iron and folic acid supplementation; LBW: Low birth weight; MAR: Missing at random; MICE: Multiple imputations by chained equations; OLS: Ordinary least squares; PCA: Principal component analysis; PIDA: Pattern imputation with 


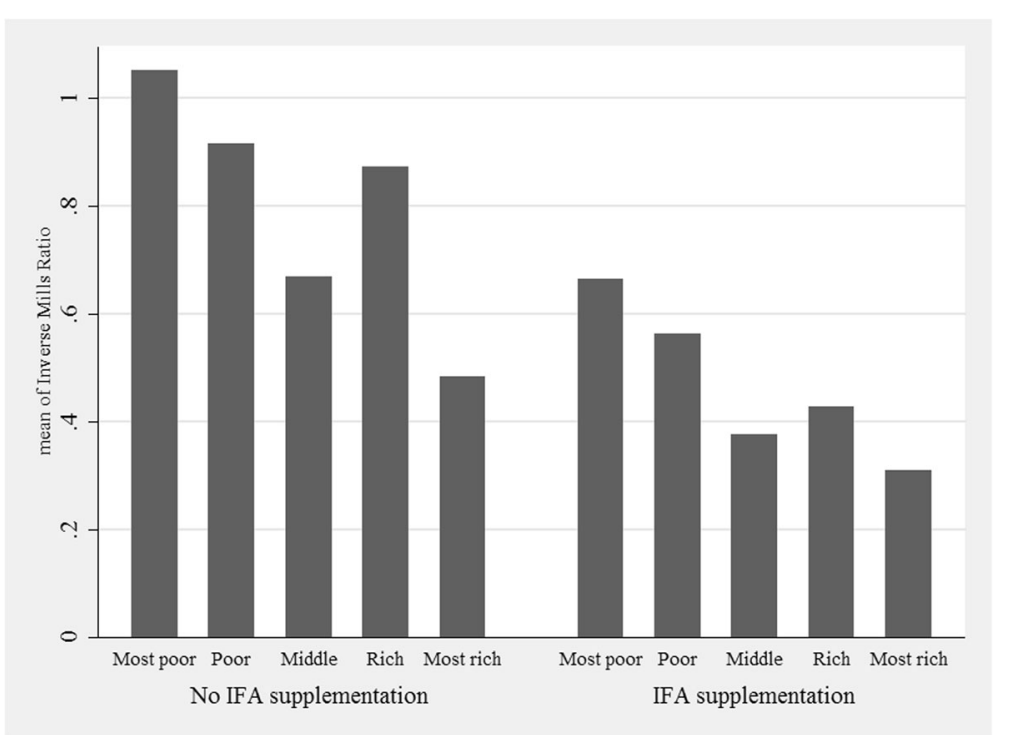

Fig. 5 Inverse Mills ratio for wealth quintile by IFAS. Shows the expected probability of selection by wealth quintile and supplementation. The average difference in the selection probabilities (likelihood of having BW data) is about 25 percentage points across all wealth quintiles, suggesting that a potentially rather different pool of women is observed in the treatment and control groups. This difference is reflected in the inverse mills ratio (IMR) correction term the Heckman model estimates in Appendix Fig. 4. The average difference in the IMR between women with IFAS and women without IFAS is 0.30 standard deviations in the unobserved latent selection trait $v$ 
Table 4 Characteristics of women who benefited from IFAS and women in the sample

\begin{tabular}{|c|c|c|c|c|c|}
\hline \multicolumn{3}{|l|}{ - } & \multicolumn{3}{|c|}{ 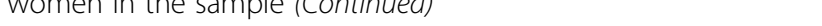 } \\
\hline & Full Sample $N=7325$ & IFAS $n=3260$ & & Full Sample $N=7325$ & IFAS $n=3260$ \\
\hline Educational attainment & & & Confirmed & $3393(46.3)$ & $1609(49.4)$ \\
\hline Never attended school & $4021(54.9)$ & $1869(57.3)$ & Not confirmed & $3932(53.9)$ & $1651(50.6)$ \\
\hline Primary school & $2203(30.1)$ & $963(29.5)$ & Persistent fever & & \\
\hline Coranic & $383(5.2)$ & $136(4.2)$ & Yes & $2198(30.0)$ & $1072(32.9)$ \\
\hline Secondary school or higher & $718(9.8)$ & $292(9.0)$ & No & $5127(70.0)$ & $2188(67.1)$ \\
\hline Literacy & & & Lack of appetite & & \\
\hline Can't write and read & 5394 (73.6) & $2494(76.5)$ & Yes & $1537(21.0)$ & $647(19.8)$ \\
\hline Can read & $342(4.7)$ & $138(4.2)$ & No & $5788(79.0)$ & $2613(80.2)$ \\
\hline
\end{tabular}

Table 4 Characteristics of women who benefited from IFAS and women in the sample (Continued)
Can write and read

$1589(21.7)$

Maternal age (years)

$15-19$
$20-34$
$35-49$

Socioeconomic status

Most poor

$1013(13.8)$

436 (13.4)

$5132(70.1)$

$1180(16.1)$

$1482(20.2)$

$1453(19.8)$

1477 (20.2)

1510 (20.6)

1403 (19.2)

787 (10.7)

$2942(40.2)$

3541 (48.3)

$55(0.8)$

294 (4.0)

5439 (74.3)

$1592(21.7)$

4198 (57.3)

2917 (39.8)

$210(2.9)$

3696 (50.5)

3629 (49.5)

$563(7.7)$

3947 (53.9)

2815 (38.4)

355 (4.8)

6970 (95.2)
2281 (70.0)

$543(16.7)$

$727(22.3)$

715 (21.9)

$665(20.4)$

$730(22.4)$

$423(13.0)$

304 (9.3)

$1336(41.0)$

1599 (49.1)

$21(0.6)$

$120(3.7)$

$2437(74.8)$

703 (21.5)

1915 (58.7)

1259 (38.6)

86 (2.6)

1618 (49.6)

1642 (50.4)

297 (9.1)

2007 (61.6)

956 (29.3)

$172(5.3)$

3088 (94.7)

Malaria 
Table 5 Associations between IFAS and low birth weight

\begin{tabular}{|c|c|c|c|c|c|c|c|c|}
\hline \multicolumn{5}{|l|}{ Logit Models } & \multicolumn{4}{|c|}{ Heckman Models } \\
\hline \multirow[t]{3}{*}{ Variable } & \multicolumn{2}{|c|}{ Unadjusted } & \multicolumn{2}{|l|}{ Adjusted } & \multicolumn{2}{|c|}{ Unadjusted } & \multicolumn{2}{|l|}{ Adjusted } \\
\hline & \multicolumn{2}{|c|}{ Risk differential } & \multicolumn{2}{|c|}{ Risk differential } & \multicolumn{2}{|c|}{ Risk differential } & \multicolumn{2}{|c|}{ Risk differential } \\
\hline & $\mathrm{dy} / \mathrm{dx}$ & $95 \% \mathrm{Cl}$ & $\mathrm{dy} / \mathrm{dx}$ & $95 \% \mathrm{Cl}$ & $\mathrm{dy} / \mathrm{dx}$ & $95 \% \mathrm{Cl}$ & $\mathrm{dy} / \mathrm{dx}$ & $95 \% \mathrm{Cl}$ \\
\hline \multicolumn{9}{|l|}{ IFA: $\mathrm{No}^{(+)}$} \\
\hline Yes & 0.076 & $-0.101 ; 0.253$ & 0.061 & $-0.184 ; 0.305$ & 0.003 & $-0.026 ; 0.031$ & $-0.104^{* * *}$ & $-0.169 ;-0.039$ \\
\hline \multicolumn{9}{|c|}{ Educational attainment: No schooling ${ }^{(+)}$} \\
\hline \multicolumn{3}{|c|}{ Primary school } & 0.064 & $-0.155 ; 0.282$ & & & 0.004 & $-0.027 ; 0.035$ \\
\hline \multicolumn{3}{|l|}{ Coranic } & 0.016 & $-0.393 ; 0.425$ & & & -0.010 & $-0.069 ; 0.049$ \\
\hline \multicolumn{3}{|c|}{ Secondary or higher } & -0.239 & $-0.574 ; 0.096$ & & & $-0.053^{* *}$ & $-0.101 ;-0.005$ \\
\hline \multicolumn{9}{|c|}{ Maternal age (years): $20-34^{(+)}$} \\
\hline \multicolumn{3}{|l|}{$15-19$} & $0.898^{* * *}$ & $0.655 ; 1.141$ & & & $0.126^{* * *}$ & $0.085 ; 0.167$ \\
\hline \multicolumn{3}{|l|}{$35-49$} & $0.569^{* * *}$ & $0.263 ; 0.875$ & & & $0.051^{* *}$ & $0.004 ; 0.099$ \\
\hline \multicolumn{9}{|c|}{ Socioeconomic status: Most poor ${ }^{(+)}$} \\
\hline \multicolumn{3}{|l|}{ Poor } & -0.161 & $-0.488 ; 0.167$ & & & -0.033 & $-0.078 ; 0.013$ \\
\hline \multicolumn{3}{|l|}{ Middle } & -0.225 & $-0.549 ; 0.100$ & & & $-0.076^{* * *}$ & $-0.126 ;-0.025$ \\
\hline \multicolumn{3}{|l|}{ Rich } & 0.004 & $-0.313 ; 0.321$ & & & $-0.051^{*}$ & $-0.102 ; 0.000$ \\
\hline \multicolumn{3}{|l|}{ Most rich } & -0.178 & $-0.561 ; 0.205$ & & & $-0.074^{* *}$ & $-0.133 ;-0.016$ \\
\hline \multicolumn{9}{|l|}{ Child sex: male } \\
\hline \multicolumn{3}{|l|}{ Female } & $0.338^{* * *}$ & $0.147 ; 0.529$ & & & $0.045^{* * *}$ & $0.019 ; 0.070$ \\
\hline \multicolumn{9}{|c|}{ Previous births: 0 child ${ }^{(+)}$} \\
\hline \multicolumn{3}{|l|}{$1-4$} & $-0.473^{* *}$ & $-0.862 ;-0.085$ & & & $-0.065^{* *}$ & $-0.125 ;-0.005$ \\
\hline \multicolumn{3}{|l|}{$\geq 5$} & $-1.283^{* * *}$ & $-1.782 ;-0.785$ & & & $-0.148^{* * *}$ & $-0.223 ;-0.072$ \\
\hline \multicolumn{9}{|c|}{ Twin births: $\mathrm{No}^{(+)}$} \\
\hline \multicolumn{3}{|l|}{ Yes } & $2.483^{* * *}$ & $2.199 ; 2.767$ & & & $0.336^{* * *}$ & $0.288 ; 0.385$ \\
\hline Constant & $-1.987^{* * *}$ & $-2.115 ;-1.859$ & $-2.287^{* * *}$ & $-2.873 ;-1.700$ & & & & \\
\hline LR test $(\mathrm{Rho}=0)$ & & & & & & & $14.59^{* * *}$ & \\
\hline observations & 4510 & & 4510 & & 4510 & & 4510 & \\
\hline
\end{tabular}

*** $p<0.01 .{ }^{* *} p<0.05 .{ }^{*} p<0.1{ }^{(+)}$Reference category; dy/dx = Marginal effect is a change in the probability of $\mathrm{Y}=1$ with a unit change in $\mathrm{X}$. Adjusted model controls for village fixed effects; $\mathrm{Cl}$ : confidence interval 
Table 6 Estimated associations with low birth weight

\begin{tabular}{|c|c|c|}
\hline \multirow[t]{2}{*}{ Variable } & \multicolumn{2}{|l|}{ Low birth weight $(95 \% \mathrm{Cl})$} \\
\hline & $\overline{M I C E}$ & Heckman model \\
\hline \multicolumn{3}{|l|}{ IFA: $\mathrm{No}^{(+)}$} \\
\hline Yes & $0.0461(-0.200 ; 0.292)$ & $\begin{array}{l}-0.104^{* * *}(-0.169 ;- \\
0.039)\end{array}$ \\
\hline \multicolumn{3}{|c|}{ Educational attainment: No schooling ${ }^{(+)}$} \\
\hline Primary & $0.073(-0.148 ; 0.294)$ & $0.004(-0.027 ; 0.035)$ \\
\hline Coranic & $0.039(-0.366 ; 0.444)$ & $-0.010(-0.069 ; 0.049)$ \\
\hline $\begin{array}{l}\text { Secondary or } \\
\text { higher }\end{array}$ & $-0.247(-0.585 ; 0.0910)$ & $\begin{array}{l}-0.053^{* *}(-0.101 ;- \\
0.005)\end{array}$ \\
\hline \multicolumn{3}{|c|}{ Maternal age (years): $20-34^{(+)}$} \\
\hline $15-19$ & $0.883^{* * *}(0.632 ; 1.134)$ & $0.126^{* * *}(0.085 ; 0.167)$ \\
\hline $35-49$ & $0.541^{* * *}(0.207 ; 0.875)$ & $0.051^{* *}(0.004 ; 0.099)$ \\
\hline \multicolumn{3}{|c|}{ Socioeconomic status: Most poor ${ }^{(+)}$} \\
\hline Poor & $-0.126(-0.479 ; 0.227)$ & $-0.033(-0.078 ; 0.013)$ \\
\hline Middle & $-0.201(-0.526 ; 0.125)$ & $\begin{array}{l}-0.076^{* * *}(-0.126 ;- \\
0.025)\end{array}$ \\
\hline Rich & $0.0348(-0.294 ; 0.364)$ & $-0.051^{*}(-0.102 ; 0.000)$ \\
\hline Most rich & $-0.123(-0.463 ; 0.218)$ & $\begin{array}{l}-0.074^{* *}(-0.133 ;- \\
0.016)\end{array}$ \\
\hline
\end{tabular}

Child sex: Male ${ }^{(+)}$

Female $\quad 0.316^{* * *}(0.144 ; 0.487) \quad 0.045^{* * *}(0.019 ; 0.070)$

Previous births: 0 child $^{(+)}$

$\begin{array}{lll}1-4 & -0.498^{* *}(-0.885 ;- & -0.065^{* *}(-0.125 ;- \\ & 0.112) & 0.005) \\ \geq 5 & -1.281^{* * *}(-1.758 ;- & -0.148^{* * *}(-0.223 ;- \\ & 0.805) & 0.072)\end{array}$

Twin births: $\mathrm{No}^{(+)}$

Yes

$$
2.463^{* * *}(2.174 ; 2.752) \quad 0.336^{* * *}(0.288 ; 0.385)
$$

observations $\quad 7325$

7325

*** $p<0.01 .{ }^{* *} p<0.05 .^{*} p<0.1 i^{(+)}$Reference category; Cl Confidence interval MICE Multiple imputation by chained equation. MICE was done with 150 imputations using Stata mi estimate package

delta adjustment; SD: Standard deviation; SERI: Research and Innovation; Swiss TPH: Swiss Tropical and Public Health Institute

\section{Acknowledgements}

The authors wish to acknowledge the population of Taabo, without which this work would not have been possible, and the HDSS team, the field enumerators, data entry, and management staff and the key informants, who are all crucial for the data collection and handling. We are deeply grateful to FAIRMED, Swiss TPH, CSRS staff, the Université Félix Houphouët- Boigny, the Health District of Tiassale and the Taabo-Cité Public Hospital, which facilitated the establishment of the Taabo HDSS.

\section{Authors' contributions}

Conceived and designed the study: SK, BB, DD, IK, and GF; conducted the study and collected data: SK, BB, DD, and IK; performed statistical analyses and summarized the data in tabular and graphical forms: SK and GF; interpreted data and prepared a first manuscript draft: SK and GF; provided important intellectual input to interpretation of findings and manuscript writing: $\mathrm{BB}, \mathrm{DD}$, and IK; reviewed and revised manuscript draft based on comments made by all authors and reviewers: SK, BB, DD, IK, and GF. All authors read and approved the final manuscript.

\section{Funding}

No specific funding was obtained for this project. The data collected with the Taabo HDSS has been supported by Fairmed, the Health District of Tiassalé, the Centre Suisse de Recherches Scientifiques en Cote d'Ivoire (CSRS), the State Secretariat for Education, Research and Innovation and the Swiss Tropical and Public Health Institute (Swiss TPH).

\section{Availability of data and materials}

The datasets used and/or analyzed during the current study are available from the corresponding author on reasonable request.

\section{Ethics approval and consent to participate}

We obtained an umbrella agreement for longitudinal monitoring of vital statistics (pregnancy, birth, death, in-migration and out-migration), healthrelated research, and public health interventions by the Comité National d'Ethique et de Recherche (CNER) in Côte d'Ivoire (reference no. 1086 MSHD/CNEF) and the Ethikkommission beider Basel (EKBB) in Switzerland (reference no. 316/08). The current project was approved by the institutional research commissions of the Centre Suisse de Recherches Scientifiques en Côte d'Ivoire (CSRS; Abidjan, Côte d'Ivoire) and the Swiss Tropical and Public Health Institute (Swiss TPH; Basel, Switzerland) and local authorities. Participation was voluntary and women identified to be pregnant were informed about the aim of the questionnaire and their rights to withdraw from the study at any time without further obligation. On top of our umbrella agreement from the national ethics committee, women provided oral informed consent and this procedure was approved prior to the start of our study.

\section{Consent for publication}

Not applicable.

\section{Competing interests}

The authors declare that they have no competing interests.

\section{Author details}

${ }^{1}$ Centre Suisse de Recherches Scientifiques en Côte d'Ivoire, 01 BP 1303, Abidjan 01, Côte d'Ivoire. ${ }^{2}$ Swiss Tropical and Public Health Institute, Basel CH - 4002, Switzerland. ${ }^{3}$ University of Basel, Basel, Switzerland.

Received: 12 January 2019 Accepted: 20 September 2019

Published online: 09 December 2019

\section{References}

1. Britton A, McKee M, Black N, McPherson K, Sanderson C. Choosing between randomised and non-randomised studies: a systematic review. Health Technol Assess. 1998;2(13), pp. i-iv, 1-124.

2. Black N. Why we need observational studies to evaluate the effectiveness of health care. BMJ. 1996;312:1215-8.

3. Benson K, Hartz AJ. A comparison of observational and randomized controlled trials. N Engl J Med. 2000;342:1878-86.

4. Crawford SL, Tennstedr SL, Mckinlay JB. A comparison of analysis methods for non-random missingness of outcome data. J Clin Epidemiol. 1995;48:209-19.

5. Donders AR, van der Heijden GJ, Stijnen T, Moons KG. Review: a gentle introduction to imputation of missing values. J Clin Epidemiol. 2006;59: 1087-91.

6. Ratitch B, O'Kelly M, Tosiello R. Missing data in clinical trials: from clinical assumptions to statistical analysis using pattern mixture models. Pharm Stat. 2013;12:337-47

7. Heckman J. Sample selection bias as a specification error. Econometrica. 1979:47:153-61.

8. Brämer GR. International statistical classification of diseases and related health problems. Tenth revision. World Health Stat Q. 1988:41:32-6.

9. Barker DJP. Fetal and infant origins of disease. London: BMJ Books; 1992.

10. Fink G, Ross R, Hill K. Institutional deliveries weakly associated with improved neonatal survival in developing countries: evidence from 192 demographic and health surveys. Int J Epidemiol. 2015;44:1879-88. https:// doi.org/10.1093/ije/dyv115. 
11. Imdad A, Bhutta ZA. Routine iron/folate supplementation during pregnancy: effect on maternal anaemia and birth outcomes. Paediatr Perinat Epidemiol. 2012;26:168-77.

12. Martinussen MP, Bracken MB, Triche EW, Jacobsen GW, Risnes KR. Folic acid supplementation in early pregnancy and the risk of preeclampsia, small for gestational age offspring and preterm delivery. Eur J Obstet Gynecol Reprod Biol. 2015;195:94-9. https://doi.org/10.1016/j.ejogrb.2015.09.022.

13. Balarajan Y, Subramanian SV, Fawzi WW. Maternal iron and folic acid supplementation is associated with lower risk of low birth weight in India. The Journal of nutrition. 2013;143:1309-1315

14. Palma S, Perez-Iglesias $R$, Prieto $D$, et al. Iron but not folic acid supplementation reduces the risk of low birthweight in pregnant women without anaemia: a case-control study. J Epidemiol Community Health. 2008;62:120-4.

15. Miranda A, Rabe-Hesketh S. Maximum likelihood estimation of endogenous switching and sample selection models for binary, ordinal, and count variables. Stata J. 2006;6:285-308,

16. Davidson RG, Shea R, Kiersten J, Eldaw S, Adam W, Agbessi A. Socioeconomic differences in health, nutrition, and population within developing countries. Washington DC: The World Bank, 20433; 2007. p. 1-4.

17. Robert Picard. GEODIST: Stata module to compute geodetic distances. https://econpapers.repec.org/software/bocbocode/s457147.htm. Accessed 17 Aug 2018.

18. Royston P. ICE: Stata module for multiple imputation of missing values; 2006. Statistical Software Components S446602, Boston College Department of Economics, revised 25 Oct 2014

19. Koné S, Baikoro N, N'Guessan Y, Jaeger FN, Silué KD, Fürst T, et al. Health \& Demographic Surveillance System Profile: the Taabo health and demographic surveillance system, Côte d'Ivoire. Int J Epidemiol. 2015;44:8797.

20. Koné S, Fürst T, Jaeger FN, Esso EL, Baikoro N, Kouadio KA, et al. Causes of death in the Taabo health and demographic surveillance system, Côte d'Ivoire, from 2009 to 2011. Glob Health Action. 2015;8:27271.

21. INDEPTH. INDEPTH resource kit for demographic surveillance systems; 2006. http://www.indepth-network.org/resources/resource-kits

22. Phillips JF, Macleod BB, Pence B. The household registration system: computer software for the rapid dissemination of demographic surveillance systems. Demogr Res. 2000;2:1-40.

23. McGovern ME, Bärnighausen T, Marra G, Radice R. On the assumption of bivariate normality in selection models: a copula approach applied to estimating HIV prevalence. Epidimiology. 2015;26(2):229-37.

24. Newey WK. Two-step series estimation of sample selection models. The Econometrics Journal. 2009;12(s1):S217-29.

25. Mishra V, Thapa S, Retherford RD, Dai X. Effect of iron supplementation during pregnancy on birthweight: evidence from Zimbabwe. Food Nutr Bull. 2005;26:338-47.

26. Peña-Rosas JP, De-Regil LM, Garcia-Casal MN, Dowswell T. Daily oral iron supplementation during pregnancy. Cochrane Database Syst Rev. 2015;7:1-544.

\section{Publisher's Note}

Springer Nature remains neutral with regard to jurisdictional claims in published maps and institutional affiliations.

Ready to submit your research? Choose BMC and benefit from:

- fast, convenient online submission

- thorough peer review by experienced researchers in your field

- rapid publication on acceptance

- support for research data, including large and complex data types

- gold Open Access which fosters wider collaboration and increased citations

- maximum visibility for your research: over $100 \mathrm{M}$ website views per year

At BMC, research is always in progress.

Learn more biomedcentral.com/submissions 